\title{
Evaluation of the traffic impact on residential building
}

\author{
Damian Beben ${ }^{1, *}$, Wojciech Anigacz ${ }^{1}$ and Piotr Bobra ${ }^{1}$ \\ ${ }^{1}$ Faculty of Civil Engineering and Architecture, Opole University of Technology, 45-061 Opole, \\ Poland
}

\begin{abstract}
The paper presents an example of evaluation of the traffic impacts on the residential building. Residents noticed numerous damage to the building, which, in their opinion, were caused by the movement of trucks from the nearby transport base of agricultural equipment's. The control seals have been glued on all cracks of the building and elements close to the road, in order to determine the damages propagation. The building and ground vibrations were established during the study. The vibration accelerations in the frequency function at the selected points of building were measured. Taking into account the dynamic impact scales (DIS), the vibration influences on the building were specified. Measurements of accelerations and vibration velocities inside a building were also conducted in order to determine the harmfulness of vibration in relation to the people. As a result of vibration accelerations test in different places of building, it was found that building is located in the first zone of the DIS, which vibrations are classified as imperceptible by the building. The harmfulness of occurring vibrations to the people staying in a residential building at the analysed road was also not found.
\end{abstract}

\section{Introduction}

Constant increase in traffic has negative effect on technical condition of residential buildings and engineering structures, as well as the comfort of life of the residents [1], [2]. It is a complex problem related to the dynamics of a structure, acoustics (influence of noise), wave propagation in ground, technical condition of a structure as well as a man's individual response to psychophysical stimuli [3]. The effect of traffic generated vibrations has already been discussed in literature on many occasions [4-7]. However, almost each individual case needs to be given individual attention because of slightly different ground and environmental conditions and, above all, of different structure and different vibrations source. Therefore the best way to evaluate the dynamic impact upon a given structure and/or people is direct measurement of acceleration (or velocity) and frequency of vibrations.

The aim of the research was: (i) to define the effect of vehicles driving along a county road on a residential building (identification of vibrations in the building and evaluation if their possible harmful effects), (ii) determination of possible propagation of damages

*Corresponding author: d.beben@po.opole.pl 
(cracks) by means of fixing control seals on cracks (iii) evaluation of technical condition of the structure of both the residential building and the road, (iv) evaluation of traffic intensity along the road near the building (measurement of traffic). Additionally effect of vibration on people staying in the considered building has been determined.

The discussed tests were undertaken in response to damage revealed in the structure of the building, caused, according to its residents, by heavy load traffic from the nearby base of vehicles and machinery used in agriculture.

\section{Description the building structure and the damages}

The discussed residential building was built before World War II and is located by a county road. Its $0.65 \mathrm{~m}$ thick walls are made of brick. The ceiling structure is made of wood. It is a storey building with no basement. It underwent reconstruction in the $90 \mathrm{~s}$ of the $20^{\text {th }}$ century in order to improve its functioning - the floor was then lowered by $0.20 \mathrm{~m}$ at the ground level and the wooden ceiling structure over the storey was elevated to reach the minimal height for usable floor space, i.e. $2.20 \mathrm{~m}$ for the ground floor and 2.40 for the first floor. Extensions of the building (without basement) are a vestibule on the ground floor and an orangery on the first floor. The building is located at a distance of $12.0 \mathrm{~m}$ from the road axis. Fig. 1 shows and overview of the building at the time of a passage of a lorry.

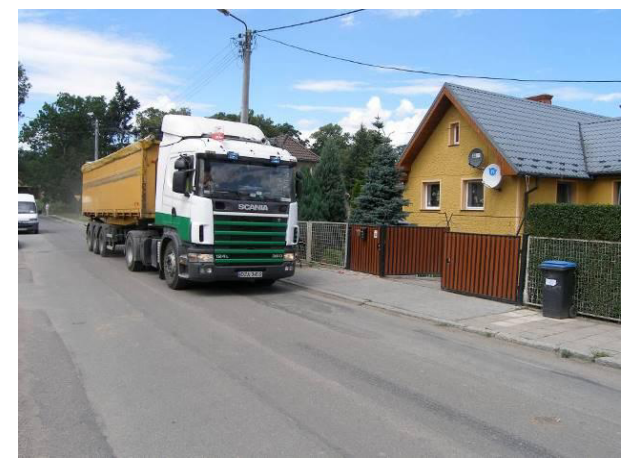

Fig. 1. The residential building at the time of vibration measurements (passage of a HGV).

In order to determine the influence of traffic on the building, a detailed inventory of the damage identified in it was undertaken. Fig. 2 shows schematic distribution of control seals on identified cracks on the building. A total number of ten control seals were attached to the damages (cracks) of the building and on elements in the proximity of the road (fence foundation), the aim of which was to determine possible propagation of damages. The control stripes (seals) of plaster were $80 \times 30 \mathrm{~mm}$ and $5 \mathrm{~mm}$ thick. The seals were secured with a transparent glass slab, at least as big as the seals. The cracks were generally classified as short and therefore the seals ( 1 or 2 ) were symmetrically fixed at the $1 / 3$ and $2 / 3$ of the crack height. Monitoring of the seals condition was held once a week over the period of two months. Fig. 3 shows example control seals on the building.

Within the period of monitoring of the seals condition, it was revealed, that the damages identified in the residential building were of non-structural nature, i.e. cracks and scratches of the coatings and plasters, relaxation of door and window mountings in the walls. These sorts of damages were observed on the first floor on the wall on the road side. Cracks on the fence foundation and the concrete floor around the building were observed too. Their dimension did not exceed $1.5 \mathrm{~mm}$. Over the period of two months of monitoring of the seals no propagation of the cracks was observed on the floor of the building while the seals 
attached outside the building (the fence foundation, the concrete floor around the building) show a minor tendency of the cracks to increase (of no more than $2 \mathrm{~mm}$ ).

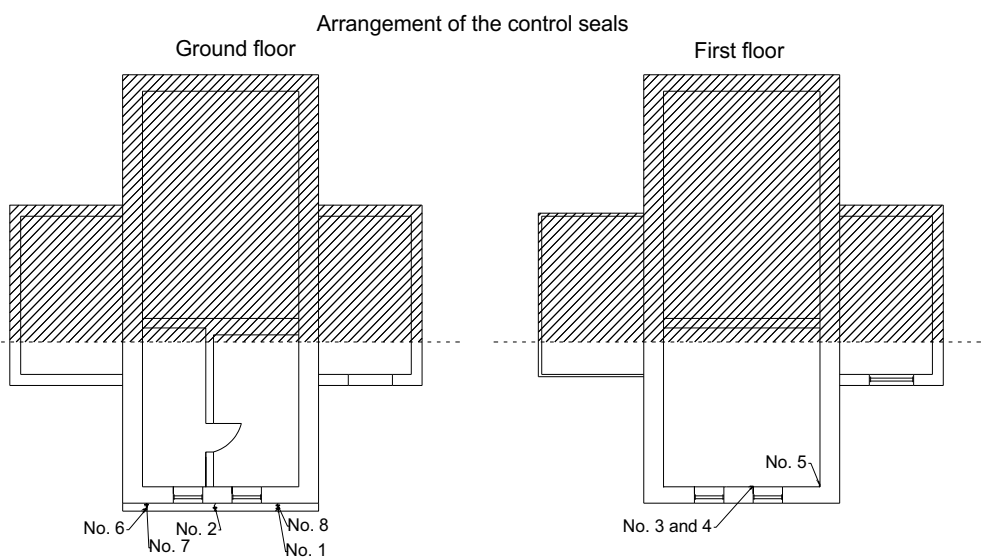

\begin{tabular}{|c|} 
No. 9 and 10 (on the fence foundation) \\
\hline \hline \\
\hline
\end{tabular}

Fig. 2. Schematic distribution of control seals.

a)

b)

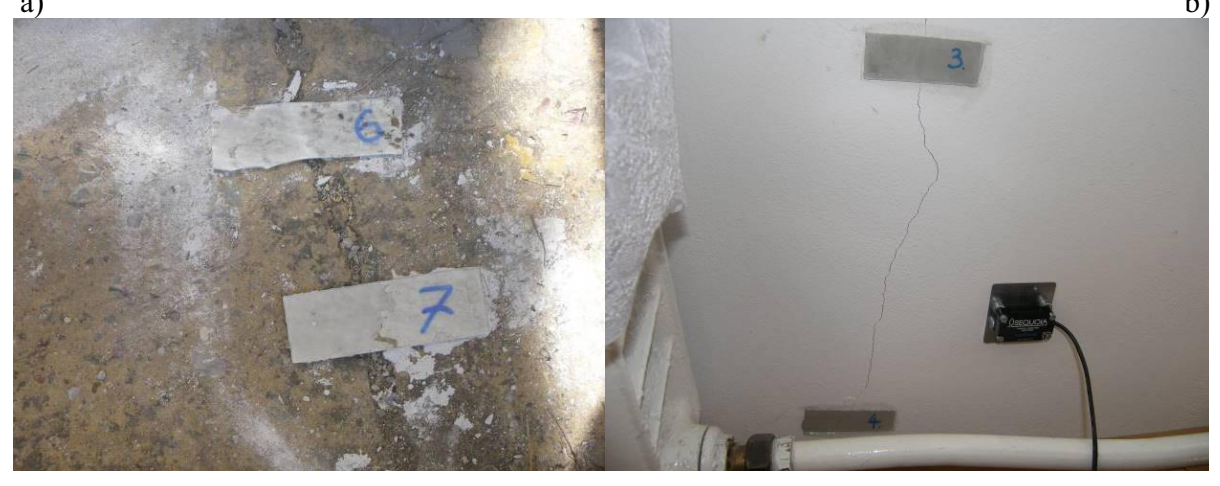

Fig. 3. The sight of control seals a) nos. 6 and 7 on concrete floor around the building (at ground level) and b) nos. 3 and 4 (in a room on the first floor of the building). The sensor to measure vibrations, located on the wall, is also visible.

In order to determine the impact of traffic upon the residential building, an inventory of damages on the road in the vicinity of the building was held (ones with potential to increase dynamic impact on the building at the time of passage of vehicles). As a result numerous examples of damage and uneven asphalt layer (caused by previous minor maintenance repairs) were identified. Fig. 4 shows typical damage and uneven surface of the considered road.

At the time of inspection of the road the following were found: (i) a number of cases of uneven surface all along the road, (ii) cavities of the surface, (iii) collapse drainage and sewage wells, (iv) lots of pollutants (sand, gravel) and vegetation near pedestrian sidewalks that hindered drainage of the road, (v) lack of cross and longitudinal slopes of roadway (or being insufficient). 
a)

b)

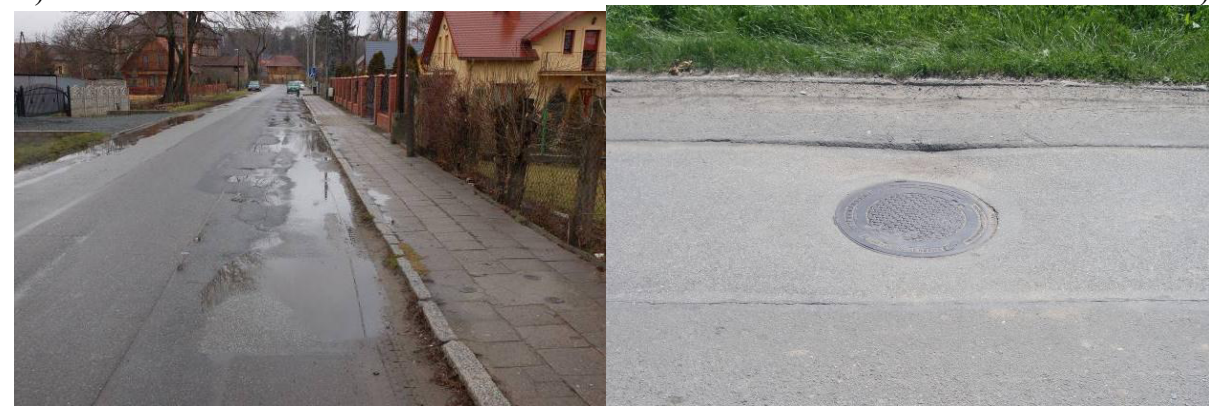

Fig. 4. Damages of the road pavement: a) cavities in asphalt filled with water (poor drainage), b) a collapsed drain.

The condition of the roadway was classified in accordance with GDPRaM (General Directorate of Public Roads and Motorways) directives [8] as at warning level - class C unsatisfactory condition i.e. roadway with major damages requiring renovation. The warning level defines a condition requiring at least a detailed examination in order to improve the condition of the roadway.

As a result, it was found that the cavities and uneven surface of the considered road as well as damages to the wells could cause increased dynamic impact. Therefore additional passages of vehicles along the damaged areas were planned.

\section{Characteristics of the traffic on the road}

Within a couple of days a complete monitoring of traffic was held to find out about its structure and to estimate its impact on the building and its residents. The most intense traffic of heavy goods vehicles (HGV) was observed around $8.00 \mathrm{a} . \mathrm{m}$. (vehicles leaving the transport base of a nearby company) and from 3 p.m. to 4 p.m. (vehicles coming back). It was observed that the total number of $21 \mathrm{HGVs}$ drove along the road within the period of observation. Other agricultural equipment (tractors with attached trailers and farming machinery) were hardly ever seen (2-4 per day). In the majority of cases the road was used by personal cars of the inhabitants of the neighbouring villages.

It should be noticed that the road is of specific location i.e. it is relatively short (approx. $180 \mathrm{~m}$ ) and it ends with double sharps which make drivers slow down to a considerable extent. This means that vehicles driving along this road do not exceed the speed of $30 \mathrm{~km} / \mathrm{h}$.

Complete traffic measurements were held twice. Categorisation of vehicles was done in accordance with GDPRaM directives [9]. The method of direct manual measurement was applied by the observers (the measurement point was located at the considered building). In accordance with GDPRaM directives for traffic measurement [9] the discussed road was classified as a type „W" section (i.e. a section that undergoes direct traffic measurement within a limited number of hours). Therefore in this case the time of measurement was limited to 8 hours (8:00 a.m. $-4: 00$ p.m.) on each of the days of measurement.

As a result of measurement of traffic structure on the discussed road it was found that: - the traffic is light most of the time - nearly $97 \%$ of all traffic and it takes place mainly between 11.00 a.m. and 3.00 p.m.,

- heavy traffic can hardly ever be observed i.e. 8-10 passages, mainly from 7.00 a.m. to 8.00 a.m. and 3.00 p.m. -4.00 p.m.,

- all-day measurement (8.00 a.m. - 4.00 p.m.) revealed 202 passages. 


\section{Measurements of the building and ground vibrations near the road}

\subsection{Impact of vibrations on the building structure}

\subsubsection{Measurement methodology}

In accordance with the Polish Norm PN-85/B-02170 [10] vibrations of a building need to be characterised by displacements (or speed or acceleration) in characteristic points of the building and a relevant frequency of vibrations. Measurement of vibrations acceleration in the function of frequency was held in order to determine the impact of vehicles driving along the discussed road onto the residential building. The measurement considered the following three passages:

(i) a car of $2.0 \mathrm{t}$ of weight driving at 20 and $40 \mathrm{~km} / \mathrm{h}$,

(ii) a combine harvester weighing $13 \mathrm{t}$ and driving at $\mathrm{z} 15 \mathrm{~km} / \mathrm{h}$ (maximum speed),

(iii) a heavy goods vehicle of $41.2 \mathrm{t}$ driving at $35-40 \mathrm{~km} / \mathrm{h}$.

In fact only a couple of lorries, most of them unloaded ( $<20 \mathrm{t}$ of weight), drive by during a day. A HGV loaded with corn (41.2 t of total weight) driving at $35-40 \mathrm{~km} / \mathrm{h}$ (more than normally) was used for tests. At the time of tests research team members informed the driver regarding a possibility to drive safely with a given speed.

For short-time vibrations i.e. the total duration of which does not exceed 3 mins $/ 24$ hours (as in the discussed case) a record was held of a chosen parameter within at least three cycles of loading i.e. chosen vehicles drove by at least three times for each measurement point. The symbols $X$ and $Y$ for horizontal measurement directions, and $Z$ for the vertical one were adopted in accordance with the Cartesian coordinate system. In the discussed case the measurement point $(X, Y)$ was located on the wall from the side of vibration source, in surrounding ground level. The signals were analysed within the scope of vibrations from $0.5 \mathrm{~Hz}$ to $100 \mathrm{~Hz}$.

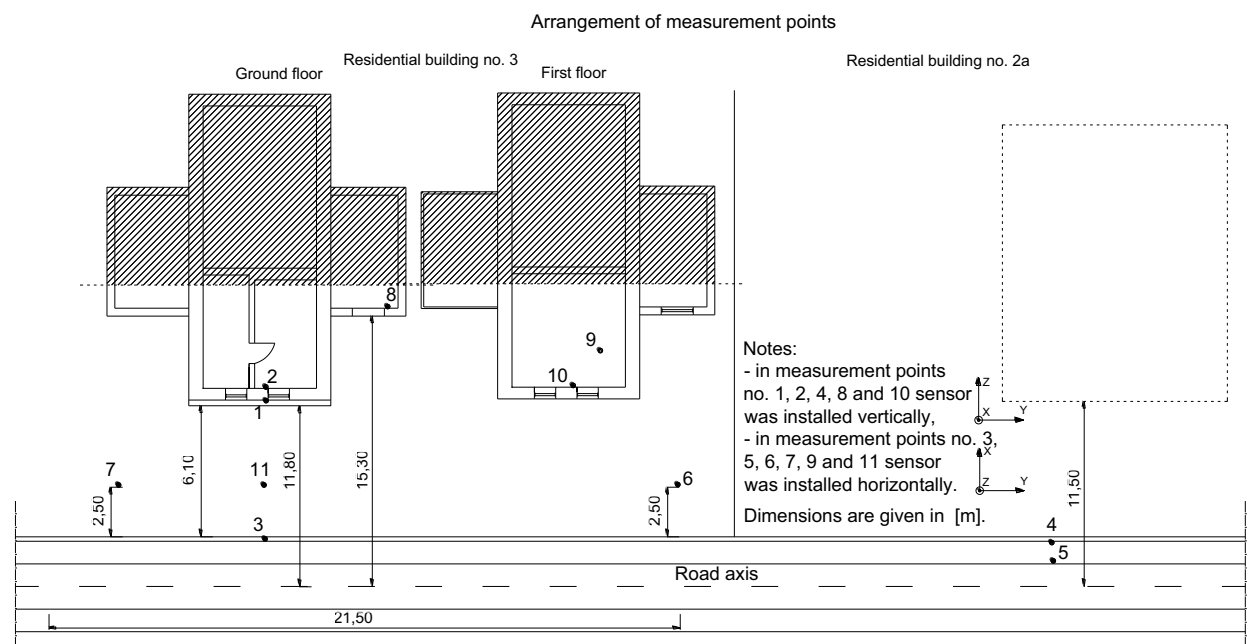

Fig. 5. Distribution of measurement points.

The measurements were held in the following test points (Fig. 5):

a) inside the building: 
- on the bearing wall at ground level (on external facade of the building - Fig. 6a) measurement point No. 1 ,

- on the bearing wall at ground level (inside the building from the side of the source of vibrations - measurement points nos. 2 and 8 ,

- on the first floor on the bearing wall (measurement point No. 10) and on the floor (measurement point No. 9) - tests related to determining the impact of vibrations on the people staying in the building,

b) on elements outside the building on the way of the wave from the source of vibrations to the entry point (the building):

- on the fence foundation (measurement points 3 and 4),

- on the pavement (measurement point no. 5) at number 2 a house,

- on a special tripod embedded in the ground (measurement points nos. 6, 7 and 11) Fig $6 b$.

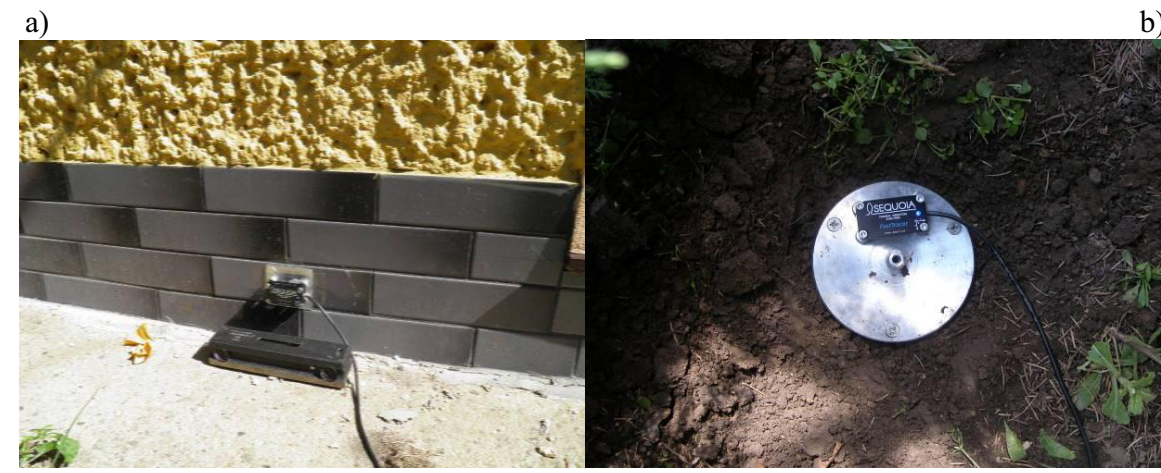

Fig. 6. Measurement points: a) no. 1 located on the wall, b) no. 6 in ground.

A FastTracer vibration sensor by Sequoia was used. It allows to measure vibrations in three independent directions at the same time. Technical data of the sensor are as follows: maximum acceleration of $+/-5 \mathrm{~g}$, frequency range of $0-2500 \mathrm{~Hz}$, resolution of 0.0025 $\mathrm{m} / \mathrm{s}^{2}$, noise of $0.075 \mathrm{~m} / \mathrm{s}^{2}$, sampling of 8192 samples $/ \mathrm{s}$.

Each measurement point was cleaned prior to installation of the sensor. The sensor was fixedly attached by means of four magnets to a metal plate, which was consequently fixed to the measurement point with use of a double-sided sticky tape. A FFT (Fast Fourier Transform) analyser was used to analyse the signals from the sensor.

\subsubsection{Approximate ways to check dynamic impact on the building}

For approximate estimation of the impact of vibrations transmitted by the ground to certain types of buildings it is allowed to apply the dynamic impact scales (DIS). The DIS scales can be used in case of masonry elements (i.e. elements for manual construction of a wall). The DIS-I scale Fig. 7) refers to a building of compact shape and of small external dimensions of its plan (below $15 \mathrm{~m}$ ), one- or two-storey one, and of height not exceeding any of the plan dimensions.

According with the PN-85 B-02170 [11], the DIS scales contain five zones limited with four limit lines (A, B, C and D). The lines have been shown in Fig. 7 within the coordinate system of vibration frequency $(f)$ and acceleration $(a)$. The coordinate values need to be determined from measurement in the points located on the structure at ground level. The following criteria were adopted for division into the zones of detrimental effect: 


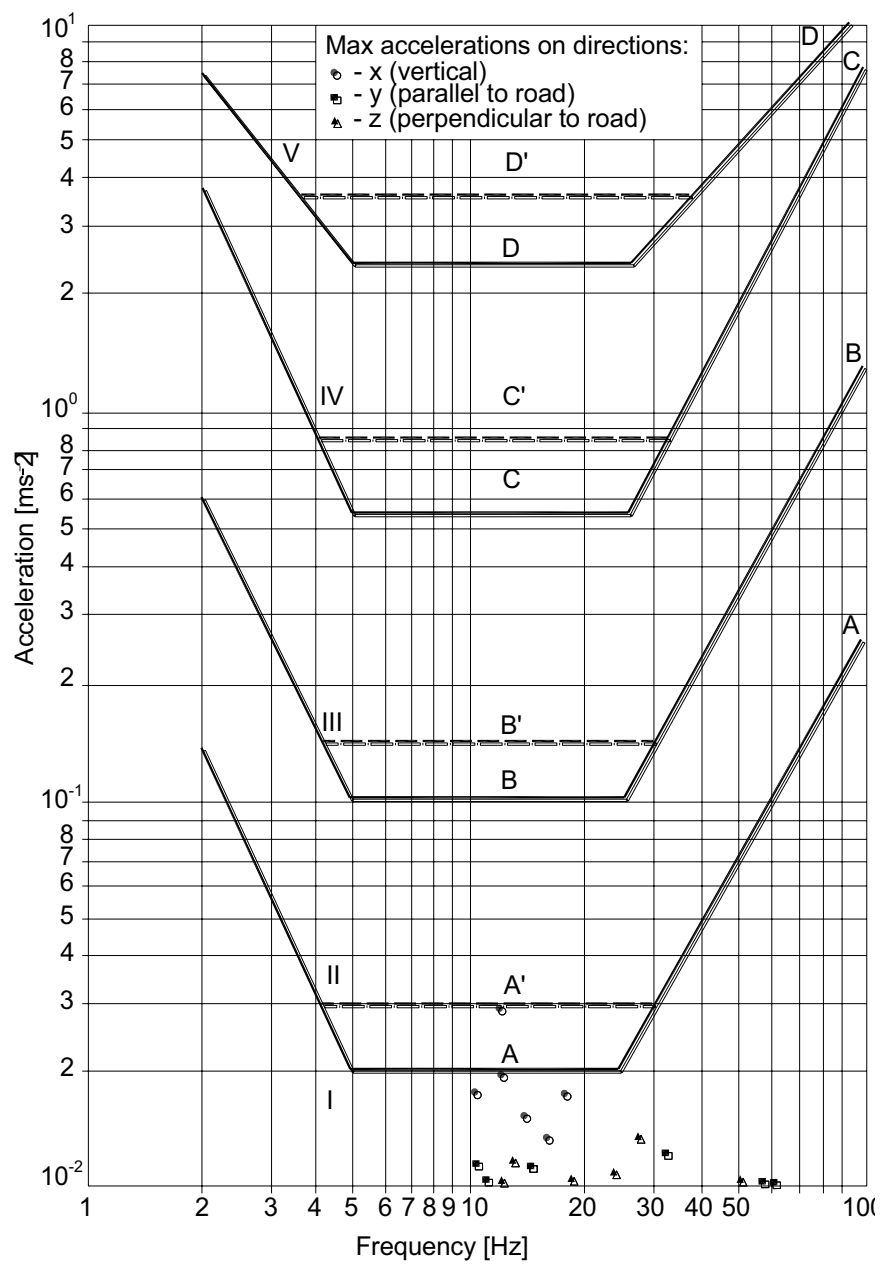

Fig. 7. Dynamic impact scales with measurement results (vibrations of the building).

a) zone I - vibrations not perceived by the structure (limit $\mathrm{A}$ - a lower limit for reception of vibrations by a building and a lower limit for considering dynamic impact. In case of vibrations below this limit, dynamic impact does not need to be considered).

b) zone II - vibrations perceptible for the building but of no harm to the structure; advanced wear of the building, first cracks in plaster and coatings etc. (limit B - the limit of the building stiffness, the lower limit for cracking and scratches in structural elements).

c) zone III - vibrations harmful to the building, they cause local scratches and cracks and therefore weaken the structure of the building and lower its load carry capacity as well as its resistance to further dynamic impact; coatings and plasters may fall off (limit C the strength limit of individual elements of the building, the lower limit of severe construction damages).

d) zone IV - vibrations highly detrimental for the building, hazardous for people. Numerous cracks, local cases of destruction of walls and individual elements of the building are observed. Hanging objects may fall down, ceiling coating may peel off, ceiling beams may slide out from bearings etc. A possibly immediate removal of vibration source or reduction of their impact is required (limit D - the limit of a 
structure stability, a lower limit of the whole structure collapse; vibrations exceeding this limit can cause construction disasters and hazards to human safety and life).

e) zone V - vibrations cause breakdown through collapse of walls, falling off ceilings etc.; total hazard to human life and safety; in case of possibility for such vibrations to appear, buildings of this type must not be used.

Zone limits have been presented in two variations, according to evaluation of the building condition, type of ground and type of vibrations. To classify a case within a specific category, a prevailing number of relevant characteristics specified in the Norm is taken into account [11].

\subsubsection{Vibration test results and analysis}

a) Vibrations of the residential building:

Due to very low values of vibration acceleration of the building structure measured in experiments, only the maximum courses of vibration acceleration were presented. In order to illustrate the level of vibrations in the building caused by passages of different vehicles, the obtained maximum acceleration results have been presented in Fig. 7 showing scales of dynamic impact (DIS). Whereas Fig. 8 shows a chosen course of vibration acceleration in the function of frequency and considers vibrations caused by a passage of a vehicle of 41.2 $\mathrm{t}$ of weight at the speed of $35-40 \mathrm{~km} / \mathrm{h}$ (measurement point no. 1).

Table 1. Comparison of maximum results of vibration acceleration in the building.

\begin{tabular}{|c|c|c|c|}
\hline Measurement point & $\begin{array}{c}\text { Frequency range } \\
{[\mathrm{Hz}]}\end{array}$ & $\begin{array}{c}\text { Amplitude of acceleration from } \\
\text { directions } Y \text { and } Z\left[\mathrm{~m} / \mathrm{s}^{2}\right]\end{array}$ & $\begin{array}{c}\text { Amplitude of acceleration } \\
\text { from direction } X\left[\mathrm{~m} / \mathrm{s}^{2}\right]\end{array}$ \\
\hline 1 (see Fig. 9) & $10-25$ & 0.009 & 0.027 \\
\hline 2 (see Fig. 10) & $10-25$ & 0.006 & 0.017 \\
\hline 8 (see Fig. 11) & $10-25$ & - & 0.014 \\
& $50-60$ & 0.004 & - \\
\hline
\end{tabular}

Note: the following indications on the axis have been adopted: $Z$ - perpendicular direction to the carriageway axis, $Y$ - parallel direction to the carriageway axis, $X$-vertical direction.

Following analysis of test results it can be noticed that the signal is dominated by components of frequency ranging from 10-25 Hz (Table 1), and the highest amplitude of acceleration from horizontal directions $(Y, Z)$ amounts at $0.009 \mathrm{~m} / \mathrm{s}^{2}$. It was registered at the time of passage of a HGV of $41.2 \mathrm{t}$ of weight at the speed of $35-40 \mathrm{~km} / \mathrm{h}$. The impact of other vehicles was at a considerably lower level i.e. acceleration did not exceed $0.003 \mathrm{~m} / \mathrm{s}^{2}$. In line with the PN-85/B-02170 [11] and Fig. 7, the examined building is located within

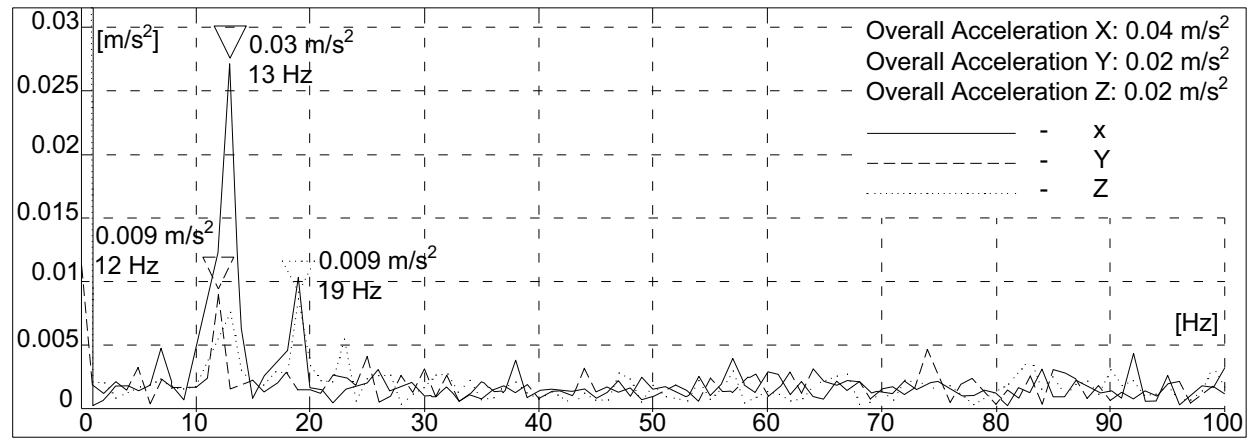

Fig. 8. Vibration accelerations course at measurement point no. 1 (foundation of the house). 
zone I of the DIS-I scale, meaning the vibrations are not perceptible to the structure. Limit A means the lower limit of vibration perceptibility for the building. Dynamic impact can be neglected when vibrations fall below this limit. However it needs to be underlined that the analysis did not consider measurement from the vertical direction, because residential buildings are designed for vertical loads (dead load, snow load, service load).

b) Measurement points located outside the building:

Figs 9-10 show extreme courses of vibration acceleration at points located outside the residential building on the way of the wave from the vibration source to the receipt point of vibration (fence foundation and at ground - see Fig. 5) caused by passage of a HGV of 41.2 $\mathrm{t}$ of weight with the speed of $35-40 \mathrm{~km} / \mathrm{h}$. The maximum values of vibration acceleration of the measurement points located outside the building have been presented in Fig. 7. Table 2 shows extreme values of vibration acceleration for the three tested dimensions in relation to the vibration source.

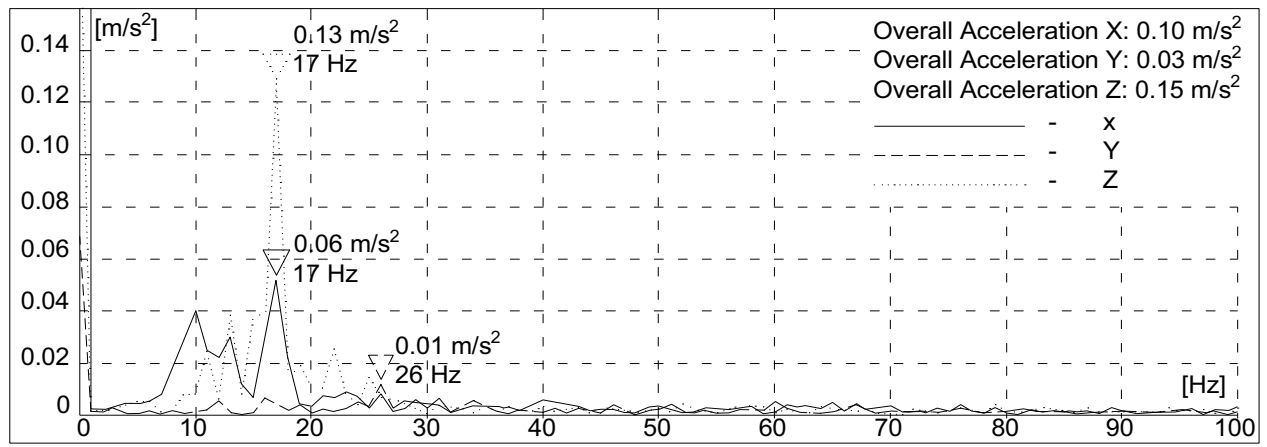

Fig. 9. Vibration accelerations course at measurement point no. 4 (foundation of the fence) (axes: $Z-$ direction perpendicular to the carriageway; $Y$ - direction parallel to the carriageway; $X$ - vertical direction).

Analysis of graphs showing spectrums of vibration acceleration from points 6, 7 and 11 (located in ground) proves that they represent a very similar level, which means that vibrations propagate in soil in a similar way. This proves that soil in the area of tests is homogeneous. Moreover, in most cases, the obtained horizontal acceleration components of vibrations in ground are smaller than $0.005 \mathrm{~g}$ ( $\mathrm{g}$ - gravitational acceleration). It should be noticed that it is not required to consider loads to a structure from vibrations transmitted through even in case of newly designed buildings.

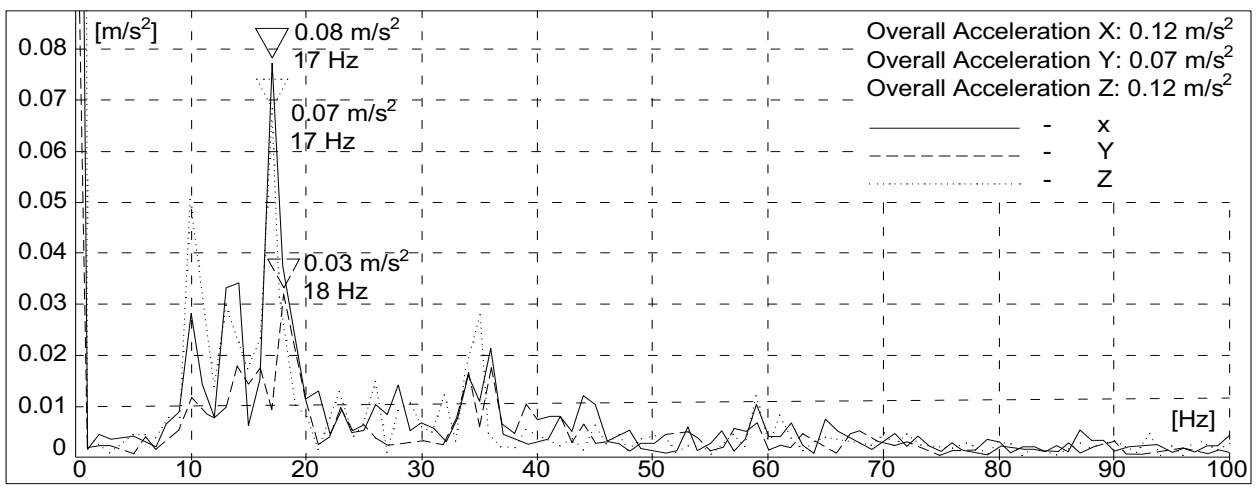

Fig. 10. Vibration accelerations course at measurement point no. 7 (in ground) (axes: $X$ - direction perpendicular to the carriageway; $Y$-direction parallel to the carriageway; $Z$ - vertical direction). 
Acceleration of vibrations of measurement points located on the fence foundation (points 3 and 4) also do not show increased values. However, it needs to be underlined that the foundation structure is not well known and can contain the eigenvalues.

Table 2. Comparison of maximum values of vibration acceleration of elements located outside the building.

\begin{tabular}{|c|c|c|c|}
\hline $\begin{array}{c}\text { Measurement } \\
\text { point number }\end{array}$ & $\begin{array}{c}\text { Frequency } \\
\text { range } \\
{[\mathrm{Hz}]}\end{array}$ & $\begin{array}{c}\text { Amplitude of vibration acceleration } \\
\text { from directions } X \text { (perpendicular) } \\
\text { and } Y \text { (parallel) to the road }\left[\mathrm{m} / \mathrm{s}^{2}\right]\end{array}$ & $\begin{array}{c}\text { Amplitude of acceleration } \\
\text { from direction } Z \text { (vertical) } \\
{\left[\mathrm{m} / \mathrm{s}^{2}\right]}\end{array}$ \\
\hline 3 & $10-15$ & 0.025 & 0.075 \\
\hline 4 & $10-25$ & 0.128 & 0.051 \\
\hline 4 & $10-25$ & 0.070 & 0.085 \\
\hline 5 & $10-20$ & 0.045 & 0.111 \\
\hline 5 & $10-30$ & 0.030 & 0.070 \\
\hline 6 & $50-65$ & 0.030 & 0.021 \\
\hline 6 & $10-25$ & 0.044 & 0.021 \\
\hline 7 & $10-25$ & 0.022 & 0.020 \\
\hline 11 & $80-85$ & 0.036 & 0.015 \\
\hline & $10-20$ & 0.077 & 0.068 \\
\hline
\end{tabular}

\subsection{Influence of vibrations on people}

\subsubsection{General remarks}

Additional measurements of vibration acceleration inside the building were held in order to determine harmfulness of vibrations related to traffic along the nearby road to people, in accordance with the Polish Norm PN-88 B-02171 [10]. Vibration velocity values inside the building were determined on the basis of integration of the measured acceleration values.

The tests were held in places where people usually stayed (on the first floor) in points of vibration transmission from the structure to a man (on the floor - measurement point no. 9 and on the wall from the side of vibration source - measurement point no. 10 (see Fig. 5)). Due to the fact that a man can change position, measurements were held also in three directions: vertical $\mathrm{Z}$ and two horizontal ( $X$ and $Y$ ) marked by eutectic system related to geometry of the place of measurement. Vibrations were measured at the time of passage of a HGV of $41.2 \mathrm{t}$ of weight at $35-40 \mathrm{~km} / \mathrm{h}$. Measurements were carried out in the least advantageous conditions in the whole evaluated frequency band for a man influenced by them. In accordance with the norm the observed vibrations were classified as intermittent i.e. of total duration time not exceeding $30 \mathrm{~min} / 24$ hours.

\subsubsection{Allowable values in accordance with the norm}

The allowable corrected value of vibration acceleration towards the vibration recipient needs to be determined on the basis of the following formula (1):

$$
a_{\mathrm{k} \text { allo. }}=a_{\mathrm{k} 1} \times n,
$$

where:

$a_{\mathrm{kl}}$ - value of acceleration relevant for vibration noticeability threshold for a man $(0.005$ $\mathrm{ms}^{-2}$ for direction $Z ; 0.0036 \mathrm{~ms}^{-2}$ for directions $X$ and $Y$ of vibration reception [10]), $n-\mathrm{a}$ factor dependent upon the type of vibrations and purpose of a place in a building (as it 
has been assumed $n=32$ - for flats and occasional vibrations of multiplicity not exceeding 10 per 24 hours [10]).

The allowable corrected acceleration value, for the $\mathrm{Z}$ direction of reception of vibrations by a man, amounts at (in the daytime): $a_{\mathrm{k} \text { allo. (Z) }}=0.005 \times 32=0.16 \mathrm{~m} / \mathrm{s}^{2}$, and for directions $X$ and $Y$ of reception of vibrations by a man, the corrected allowable value of acceleration amounts at (in the daytime): $a_{\mathrm{k} \text { allo. } \mathrm{X}, \mathrm{Y})}=0.0036 \times 32=0.1152 \mathrm{~m} / \mathrm{s}^{2}$. Whereas the corrected allowable values of vibration velocity towards the reception point of vibrations can be determined on the basis of the following formula (2):

$$
V_{\mathrm{k} \text { allo. }}=V_{\mathrm{kl}} \times n,
$$

where:

$V_{\mathrm{kl}}$ - the value of velocity corresponding with noticeability threshold in a man $\left(0.0001 \mathrm{~ms}^{-1}\right.$ for direction $Z ; 0.00029 \mathrm{~ms}^{-1}$ for directions $X$ and $Y$ of vibration reception [10]), $n$ - factor accepted as in formula (1).

The corrected allowable value of vibration velocity for direction $Z$ of reception of vibration by a man amounts at (in the daytime): $V_{\mathrm{k} \text { allo. (Z) }}=0.0001 \times 32=0.0032 \mathrm{~ms}^{-1}=3.2$ $\mathrm{mms}^{-1}$, and for direction $X$ and $Y$ of reception of vibrations by a man, the corrected allowable value of vibration velocity (in the daytime), amounts at: $V_{\mathrm{k} \text { allo. }(\mathrm{X}, \mathrm{Y})}=0.00029 \times$ $32=0.00928 \mathrm{~ms}^{-1}=9.28 \mathrm{mms}^{-1}$.

\subsubsection{Measurements results and analysis}

Fig. 11 and Table 3 show maximum vibration acceleration obtained for measurement point no. 9 located on the first floor of the building, on the floor from the vibration source side.

Table 3. Maximum vibration acceleration values at measurement point no. 9 (the floor).

\begin{tabular}{|c|c|c|}
\hline $\begin{array}{c}\text { Frequency } \\
{[\mathrm{Hz}]}\end{array}$ & $\begin{array}{c}\text { The highest amplitude of acceleration from } \\
\text { perpendicular direction } X \text { and the direction } \\
\text { Y parallel to the carriageway }\left[\mathrm{m} / \mathrm{s}^{2}\right]\end{array}$ & $\begin{array}{c}\text { The highest amplitude of } \\
\text { acceleration from the vertical } \\
\text { direction } \mathrm{Z}\left[\mathrm{m} / \mathrm{s}^{2}\right]\end{array}$ \\
\hline 6 & 0.005 & 0.010 \\
10 & 0.007 & 0.005 \\
11 & & 0.008 \\
13 & & 0.007 \\
18 & & 0.007 \\
20 & 0.006 & 0.009 \\
82 & & 0.024 \\
84 & & 0.015 \\
15 & 0.005 & 0.009 \\
17 & & 0.008 \\
67 & & 0.009 \\
88 & & 0.020 \\
93 & & 0.010 \\
95 & & 0.054 \\
\hline 79 & & 0.008 \\
\hline 9 & & 0.028 \\
67 & & 0.022 \\
\hline 6 & & \\
\hline
\end{tabular}

Whereas the maximum values of vibration velocity have been presented in Table 4 . They were observed at the measurement point no. 9 located on the first floor of the residential building (on the floor surface) by the discussed road. 


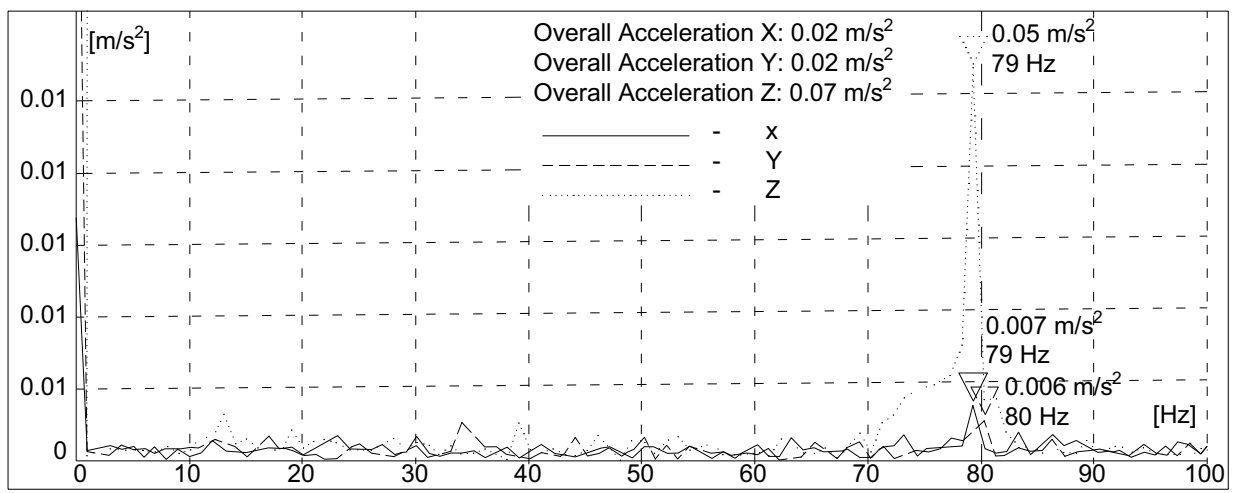

Fig. 11. Vibration accelerations course at measurement point no. 9 (the floor) - passage of a HGV over a collapsed drain.

Table 4. Maximum values of vibration velocity at the measurement point no. 9 (the floor).

\begin{tabular}{|c|c|c|c|c|}
\hline \multirow[t]{2}{*}{ Load description } & \multicolumn{2}{|c|}{$\begin{array}{l}\text { Amplitude of vibration velocity } \\
\text { from perpendicular direction } X \text { and } \\
\text { direction } Y \text { parallel to the } \\
\text { carriageway }[\mathrm{mm} / \mathrm{s}]\end{array}$} & \multicolumn{2}{|c|}{$\begin{array}{l}\text { Amplitude of vibration velocity } \\
\text { from vertical direction } Z[\mathrm{~mm} / \mathrm{s}\end{array}$} \\
\hline & $\begin{array}{c}\text { Extreme } \\
\text { value }\end{array}$ & $\begin{array}{c}\text { Effective value of the } \\
\text { signal RMS }\end{array}$ & $\begin{array}{c}\text { Extreme } \\
\text { value }\end{array}$ & $\begin{array}{l}\text { Effective value of } \\
\text { the signal RMS }\end{array}$ \\
\hline $\begin{array}{c}\text { (normal passage of a vehicle } \\
\text { of } 41.2 \mathrm{t} \text { of weight }\end{array}$ & $\begin{array}{l}0.399 \\
0.333 \\
\end{array}$ & $\begin{array}{l}0.269 \\
0.242 \\
\end{array}$ & 0.632 & 0.540 \\
\hline $\begin{array}{c}\text { (passage of a vehicle of } 14 \mathrm{t} \\
\text { of weight over a drain) }\end{array}$ & $\begin{array}{l}0.354 \\
0.294 \\
\end{array}$ & $\begin{array}{l}0.207 \\
0.178 \\
\end{array}$ & 0.461 & 0.288 \\
\hline $\begin{array}{c}\text { (passage of a vehicle of } 41.2 \\
\text { t of weight over a drain) }\end{array}$ & $\begin{array}{l}0.309 \\
0.239\end{array}$ & $\begin{array}{l}0.189 \\
0.163\end{array}$ & 0.439 & 0.324 \\
\hline $\begin{array}{c}\text { (passage of a vehicle of } 41.2 \\
\text { t of weight over a drain) }\end{array}$ & $\begin{array}{l}0.239 \\
0.292 \\
\end{array}$ & $\begin{array}{l}0.142 \\
0.179 \\
\end{array}$ & 0.441 & 0.287 \\
\hline
\end{tabular}

In the process of analysis of the obtained results of vibration acceleration and velocity, the following has been found:

- for the vertical direction $(Z)$ of vibration reception by a man, the corrected allowable vibration acceleration value amounts at $0,16 \mathrm{~m} / \mathrm{s}^{2}$, and is in all cases higher than one received in tests. Similarly the allowable value of vibration velocity being $3.2 \mathrm{~mm} / \mathrm{s}$ was not exceeded in any of the case of passage of a loading vehicle. It needs to be underlined that a HGV of $41.2 \mathrm{t}$ of weight was used in the tests, which, along with standard passages, did an additional passage over a collapsed drain (constituting a so called impact, i.e. increased dynamic influence).

- for perpendicular and parallel directions $(X$ and $Y)$ of vibration reception by a man , the corrected allowable value of vibration acceleration amounts at $0.1152 \mathrm{~m} / \mathrm{s}^{2}$, and is, in all discussed cases, higher than maximum results obtained from tests. The allowable value of vibration velocity of $9.28 \mathrm{~mm} / \mathrm{s}$ also was not exceeded in any of the considered instances of vehicle passage.

\section{Conclusions}

Based on the conducted tests and observations, the following conclusions have been drawn:

1. As a result of examination of vibration acceleration in different parts of the residential building, it was found that the building falls within zone I of the DIS-I scale, which 
means that vibrations are classified as unnoticeable for the structure (in line with Polish Norm PN-85/B-02170 [11]). It needs to be mentioned that the extreme values of vibrations were observed during passage of a loaded HGV of $41.2 \mathrm{t}$ of total weight. Passages of other cars and heavy vehicles caused smaller values of vibrations.

2. As a result of additional measurements of vibration acceleration of soil, it was found that the values represent a similar level, which proves homogeneity of soil and therefore similar propagation of vibrations within. The values of vibration acceleration in majority of cases do not exceed $0.005 \mathrm{~g}$, which is a condition for newly designed buildings.

3. No harmful effects of vibrations on people residing in the house by the discussed road have been proved. The obtained values of acceleration and velocity were smaller than permitted ones. It needs to be mentioned that a HGV of $41.2 \mathrm{t}$ of weight was used during the tests. What is more, one of its passages was over a collapsed drain, causing an increased dynamic impact.

4. The damages found in the residential building were classified as non-structural, i.e. scratches and cracks in plasters and coatings. Monitoring of propagation of cracks held within the period of two months did not prove the damages would have a tendency to develop. The road pavement condition was classified at warning level in line with GDPRaM directives [8]. Numerous cases of surface roughness, cavities in pavement, collapsed drainage and sewage wells were observed.

5. It is recommended that the considered road is renovated, with special attention to drainage and sewage wells and cavities in the asphalt pavement, and with modelling of relevant cross and longitudinal downgrades. In the light of tests and analyses, it does not seem to be advisable to limit load of vehicles moving along the road. Moreover, it is suggested to undertake tests of noise level which probably causes poor psychophysical sensations in the residents.

\section{References}

1. B. Xia, P.B. Wei, Y.M. Cao, Traffic-induced vibrations of ground environments and buildings, Environmental vibrations: Prediction, monitoring, mitigation and evaluation (Taylor \& Francis Group, London, 529-539, 2005)

2. O. Hunaidi, Traffic vibrations in buildings (National Research Council, 2000)

3. Z. Engel, Environmental protection against vibrations and noise (PWN, Warsaw 2001)

4. O. Hunaid, M. Tremblay, Traffic-induced building vibrations in Montreal, Can. J. Civ. Eng. 24, 736-753 (1997)

5. R. Ciesielski, E. Maciąg, Road vibrations and their effects on buildings (WKŁ, Warsaw, 1990)

6. H. Hao, T.C. Ang, J. Shen, Building vibration to traffic-induced ground motion, Build. Environ. 36, 321-336 (2001)

7. M. Petronijević, M. Nefovska-Danilović, M. Radišić, Analysis of frame structure vibrations induced by traffic, Gradevinar, 65, 811-824 (2013)

8. M. Radzikowski, The evaluation of the surface SOSN - application guidelines (GDPRaM, Warsaw, 2010)

9. Guidelines for measuring traffic, Ministry of Infrastructure, Department of Roads and Highways, Warsaw (2009)

10. PN-88 B-02171, Evaluation of vibration influence on people in buildings (Polish Committee for Standardization of Measurement and Quality, Warsaw, 1988)

11. PN-85 B-02170, Evaluation of the harmfulness of building vibrations due to ground motion (Polish Committee for Standardization of Measurement and Quality, Warsaw, 1985) 